\title{
The Role of Radionuclide Imaging in Epilepsy, Part 2: Epilepsy Syndromes
}

\author{
Ajay Kumar and Harry T. Chugani \\ PET Center, Department of Pediatrics, Neurology, and Radiology, Children's Hospital of Michigan, Detroit Medical Center, Wayne \\ State University School of Medicine, Detroit, Michigan
}

\begin{abstract}
CE credit: For CE credit, you can access the test for this article, as well as additional JNMT CE tests, online at https://www.snmmilearningcenter.org. Complete the test online no later than March 2020. Your online test will be scored immediately. You may make 3 attempts to pass the test and must answer $80 \%$ of the questions correctly to receive $1.0 \mathrm{CEH}$ (Continuing Education Hour) credit. SNMMI members will have their CEH credit added to their VOICE transcript automatically; nonmembers will be able to print out a CE certificate upon successfully completing the test. The online test is free to SNMMI members; nonmembers must pay $\$ 15.00$ by credit card when logging onto the website to take the test.
\end{abstract}

PET and SPECT can play an important role in the evaluation of various epileptic syndromes, particularly those with unknown causes, by revealing various underlying abnormalities that may not be fully appreciated from MR imaging studies. In some cases, PET and SPECT provide crucial data that guide surgical resections of the epileptogenic zone for medically refractory epilepsy. In other cases, these neuroimaging modalities preclude a surgical option and can guide genetic studies. Longitudinal PET and SPECT studies may increase our understanding of the etiopathogenesis of epilepsy syndromes and provide a clearer picture of the natural history of neurologic progression.

Key Words: epilepsy; epilepsy syndromes; epilepsy surgery; FDG; PET; radionuclide; seizure; SPECT

J Nucl Med Technol 2017; 45:22-29

DOI: 10.2967/jnumed.113.129593

$\mathbf{T}$ he role of radionuclide imaging with PET and SPECT in patients with various epilepsy syndromes will be discussed in this review.

\section{EPILEPSY SYNDROMES}

\section{Epileptic Spasms}

Epileptic spasms are seizures characterized by clusters of short contractions typically involving the head, trunk, and extremities. Previously called infantile spasms, epileptic spasms is the preferred term because they can occur or persist beyond infancy. Epileptic spasms can occur in isolation or as part of West syndrome, which is the triad of epileptic

Received Jul. 17, 2013; revision accepted Jul. 31, 2013.

For correspondence or reprints contact: Ajay Kumar, Department of Pediatrics, Neurology, and Radiology, Wayne State University School of Medicine, PET Center, Children's Hospital of Michigan, Detroit, MI 48201. E-mail: ajay@pet.wayne.edu

COPYRIGHT (C) 2017 by the Society of Nuclear Medicine and Molecular Imaging. spasms, an electroencephalogram (EEG) pattern of hypsarrhythmia, and developmental arrest. Epileptic spasms are referred to as symptomatic if associated with an underlying condition (e.g., tuberous sclerosis, Down syndrome, or brain injury) or as having an unknown cause when no underlying etiology can be determined. In rare cases, there may be no underlying etiology and the spasms are a transient manifestation of a neurophysiologic immaturity that resolves readily with treatment such as adrenocorticotropic hormone or vigabatrin, without any subsequent adverse outcome (idiopathic epileptic spasms) $(1,2)$. However, in many patients, this condition is neurologically and developmentally devastating because clusters of hundreds of spasms occur each day.

PET Imaging. PET can play an important role in the evaluation of children with epileptic spasms, particularly when there is no known cause $(3,4)$. Epileptic spasms, because of their bilateral and relatively symmetric clinical semiology, have traditionally been classified as a form of generalized seizure. However, after the study by Chugani et al. (4), it became apparent that in a subset of patients, epileptic spasms may be a form of secondary generalized seizure propagating from cortical lesions not always apparent on MR imaging but readily appreciated on ${ }^{18}$ F-FDG PET scans (Fig. 1). In that report, unilateral cortical areas of glucose hypometabolism were demonstrated in 5 children with intractable epileptic spasms (normal MR imaging results in 4/5). Four of these 5 children underwent resection of the cortical areas of glucose hypometabolism, guided by intracranial electrocorticography, resulting in freedom from seizures or improvement of seizure control. Neuropathologic examination of the resected brain tissue showed cortical dysplasia. A subsequent study on a large number of patients with spasms $(n=140)$ found that among the 97 cases classified as "spasms with unknown causes," 95\% showed uni- or multifocal areas of cortical metabolic abnormalities (5). Four different patterns of ${ }^{18} \mathrm{~F}$ FDG hypometabolism were observed: unifocal in $20 \%$ of these 


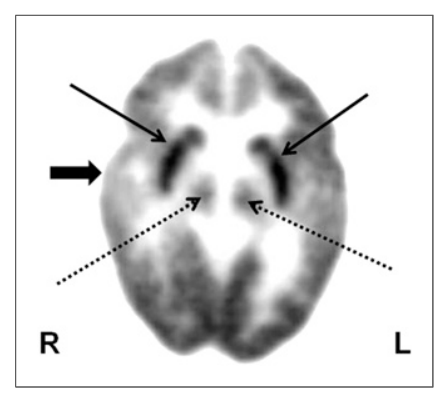

basal ganglia (thin solid arrows) dashed arrows) likely implicates their role in spasm gen (thin

children, multifocal in $65 \%$, diffuse in $5 \%$, and bitemporal hypometabolism in $10 \%$ (5). The unifocal PET abnormalities are believed to be due to underlying cortical dysplasia. The recognition that a subset of patients with intractable epileptic spasms may harbor a potentially resectable focal lesion has changed the general nonsurgical therapeutic approach in these patients by trying to identify these surgical candidates to improve their outcome. ${ }^{18} \mathrm{~F}$-FDG PET may show a wider area of hypometabolism or may show a combination of hypo- and hypermetabolism when an infant is studied during active spasms, compared with an interictal state. Therefore, in potential surgical candidates, ictal PET studies may overestimate the epileptogenic zone. The surgical removal of focal brain lesions not only leads to cessation of the spasms but also to improved neurocognitive outcome $(3,6-16)$. Occasionally, patients with a multifocal pattern can also be considered for palliative surgery, if most of the seizures originate from a single region, with improved quality of life but guarded developmental outcome (17). On the other hand, the diffuse metabolic pattern is likely associated with underlying metabolic, genetic, or neurodegenerative pathology. Interestingly, some children show bitemporal hypometabolism and a distinct clinical phenotype characterized by severe developmental delay, particularly in the language domain, and autism or pervasive developmental disorder (18). These children are unlikely surgical candidates and should be explored with alternative therapeutic options.

SPECT Imaging. Interictal SPECT studies have shown perfusion abnormalities ranging from cortical hypoperfusion (19-24) to cortical hyperperfusion (19). Ictal SPECT has shown areas of cortical hyperperfusion, with occasional hyperperfusion of the subcortical structures $(20,21)$.

PET and SPECT can also shed some light on the possible pathomechanism of epileptic spasms, particularly regarding the probable origin and propagation of electrical events responsible for spasms. For example, these patients may show a focal cortical hypometabolism along with prominent glucose metabolism in the lenticular nuclei and brain stem, suggesting complex cortical-subcortical interactions (Fig. 1) (25). Basal ganglia and brain stem involvement likely suggests their role in the secondary generalization of focal cortical discharges, resulting in spasms. It appears that the spasms result primarily from focal or diffuse cortical abnormalities interacting with the brain stem and lenticular nuclei and that this type of generalization accounts for the bilateral motor involvement and relative symmetry of most spasms even in the presence of a discrete focal lesion (25). It is hypothesized that during a critical stage of brain development (beginning at about $3 \mathrm{mo}$, when cortical maturation becomes evident on ${ }^{18} \mathrm{~F}-\mathrm{FDG}$ PET scans), the primary cortical focus interacts through its epileptic discharges with brain stem structures, particularly the raphe nuclei, which have strong cortical projections. The raphecortical and corticocortical propagation may be responsible for the EEG feature of hypsarrhythmia. The raphe nuclei also have projections to the striatal region (bilateral putamen), and these pathways may activate descending spinal pathways bilaterally to result in the bilateral and relatively symmetric clinical semiology of epileptic spasms. Recent studies using a combination of interictal and ictal SPECT also found ictal hyperperfusion of a cortical lesion and basal ganglia, supporting the notion that secondary generalization from a cortical focus may account for the spasms $(26,27)$. The finding of localized cortical perfusion defects in some children with West syndrome confirms that focal cortical lesions play an important role in its development (28). Interestingly, in infants, hyperperfusion has been found interictally in the area of cortical dysgenesis and appears to be specific for this young population $(22,28)$. These findings corroborate the notion that infantile spasms result from complex cortical-subcortical interaction, with age and brain maturity playing an important role. Rapid involvement of the basal ganglia and brain stem likely results in the secondary generalization of a seemingly partial seizure arising from a focal cortical lesion (25); however, what leads to this interaction has yet to be determined.

\section{Tuberous Sclerosis}

Tuberous sclerosis complex is an autosomal-dominant multiorgan disorder characterized by the development of nonmalignant tumors or tubers in various organs, including the brain. Epilepsy develops in $80 \%-90 \%$ of these patients, in some as early as infancy $(29,30)$, and the epilepsy becomes intractable in $50 \%-80 \%$ of cases. Because intractable seizures have a detrimental effect on neurocognitive development, these patients can potentially benefit from early epilepsy surgery (31). However, usually it is difficult to localize the epileptogenic focus because of the multiplicity of cortical tubers, even though a single tuber may be epileptogenic, as indicated by surgical outcome studies showing good seizure outcome after resection of the suspected epileptogenic tubers and leaving the nonepileptogenic ones in place (32-36). In these cases, radionuclide studies can play a valuable role by noninvasively lateralizing and localizing the epileptogenic tuber.

PET Imaging. ${ }^{18} \mathrm{~F}-\mathrm{FDG}$ PET can identify the cortical tubers, including smaller ones not visualized on T2-weighted MR imaging or even fluid-attenuated inversion recovery images (37-41). Typically, cortical tubers are seen as multifocal areas of glucose hypometabolism (Fig. 2) $(42,43)$, which is 


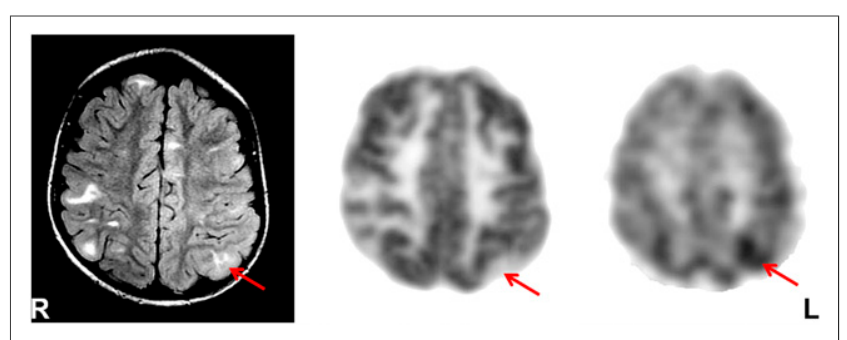

FIGURE 2. Fluid-attenuated inversion recovery (FLAIR) MR imaging (left), ${ }^{18} \mathrm{~F}-\mathrm{FDG}$ PET (middle), and ${ }^{11} \mathrm{C}-\mathrm{AMT}$ PET (right) in tuberous sclerosis patient with multiple brain tubers (enhancing lesions on FLAIR MR imaging), intractable epilepsy, and nonlocalizing scalp EEG. Although ${ }^{18} \mathrm{~F}-\mathrm{FDG}$ PET showed hypometabolism in all tubers and overlying cortices, interictal ${ }^{11} \mathrm{C}$-AMT PET revealed increased ${ }^{11} \mathrm{C}$-AMT uptake in left parietal tuber (arrow) only, which likely is epileptogenic, considering the almost $100 \%$ specificity of this test in detecting epileptogenic tubers. Most of the increased ${ }^{11} \mathrm{C}-\mathrm{AMT}$ uptake is at edge (anteromedial in this case) of tuber, with remainder showing less ${ }^{11} \mathrm{C}-\mathrm{AMT}$ uptake.

hypothesized to be due to the decreased number of neurons and simplified dendritic pattern within the tubers, and hence less requirement for glucose; however, the area of glucose hypometabolism is usually larger than the lesions seen on MR imaging (37). Furthermore, ${ }^{18} \mathrm{~F}-\mathrm{FDG}$ PET allows detection not only of the cortical tubers but also of dysplastic cortex, which is frequently seen in these patients and may appear normal on MR imaging. Although ${ }^{18}$ F-FDG PET cannot distinguish between epileptogenic and nonepileptogenic tubers, as all tubers appear hypometabolic, it can assess the full extent of functional abnormalities in the brain and evaluate the integrity of the homotopic cortex if surgical resection is planned, thereby predicting potential postoperative cognitive deficits.

Another PET tracer, ${ }^{11} \mathrm{C}$-alphamethyl-L-tryptophan $\left({ }^{11} \mathrm{C}\right.$ AMT), has been found to be useful in this condition, as it shows increased tracer uptake, interictally, in epileptogenic tubers only (Fig. 2) (37,44,45), sometimes only at one edge and with some involvement of the adjacent apparently normal cortex, turning out to be dysplastic on histopathologic examination (33). The increased ${ }^{11} \mathrm{C}$-AMT uptake in the tubers appears to be due to the activation of the kynurenine pathway, leading to the production of quinolinic acid, a proconvulsant, in the tuber and dysplastic cortex (46). ${ }^{11} \mathrm{C}$-AMT PET with quantitative evaluation of lesional uptake levels can identify epileptogenic tubers in almost two thirds of children with tuberous sclerosis and intractable epilepsy and is almost $100 \%$ specific $(37,45,46)$. Tubers with at least a $10 \%$ increase in ${ }^{11} \mathrm{C}$-AMT uptake appear to be invariably epileptogenic, and a cutoff threshold of 1.02 for the ${ }^{11} \mathrm{C}$-AMT uptake ratio appears to provide $83 \%$ accuracy for detecting tubers that need to be resected to achieve a seizure-free outcome $(33,37)$. The high specificity of increased ${ }^{11} \mathrm{C}$-AMT uptake is also suggested by the good correlation between resection of epileptogenic tubers, showing increased ${ }^{11} \mathrm{C}$-AMT uptake, and seizure outcome (33). However, its sensitivity is suboptimal, likely depending on the underlying pathology and method of data analysis. It appears that MR imagingbased quantitative assessment can increase the sensitivity of ${ }^{11} \mathrm{C}$-AMT PET to $79 \%$, from $44 \%$ with visual assessment (47). This greater sensitivity may be related to the fact that nonepileptic tubers show decreased ${ }^{11} \mathrm{C}$-AMT uptake and that the epileptogenic ones with ${ }^{11} \mathrm{C}$-AMT uptake that is relatively increased, but still close to the level in the surrounding normal cortex, may be missed on visual analysis.

The use of PET in tuberous sclerosis complex has also increased our understanding of the neurobehavioral phenotypes of tuberous sclerosis complex, including autism, attention deficit hyperactivity disorder, aggression, and cognitive impairment. These PET studies have expanded our understanding of the pathophysiology of autism in tuberous sclerosis complex, pointing to both cortical and subcortical dysfunction (48). Autistic features consisting of stereotyped behavior, impaired social interaction, and communication disturbance have been found to be correlated with glucose hypermetabolism in the deep cerebellar nuclei and increased ${ }^{11} \mathrm{C}$-AMT uptake in the caudate nucleus (48). Further, compared with left-sided cerebellar lesions, rightsided cerebellar lesions have been observed to be associated with higher social isolation and with communicative and developmental disturbances (49).

SPECT Imaging. SPECT can also play an important role in identifying epileptic tubers, by showing them hyperperfused during the ictal phase $(36,50,51)$. A good correlation has been reported between ictal SPECT and ictal scalp EEG $(26,51)$. SISCOM (subtraction ictal SPECT coregistered to MR imaging; that is, the interictal SPECT images are subtracted from the ictal images and the results are displayed on coregistered MR images) further increases the usefulness of SPECT in identifying the epileptogenic zone and in guiding the location and extent of epilepsy surgery in children with tuberous sclerosis complex and multifocal abnormalities (50). Complete resection of the SISCOM hyperperfusion abnormality has been found to be associated with seizure-free outcome. Several ${ }^{123}$ I-iomazenil SPECT studies have found decreased $\gamma$-aminobutyric acid receptor binding in and around cortical tubers (52,53), suggesting that benzodiazepine receptor expression is abnormal and that decreased neuronal inhibition may have a role in epileptogenicity in this condition.

\section{Lennox-Gastaut Syndrome}

Lennox-Gastaut syndrome is characterized by a triad of multiple seizure types including tonic seizures, developmental delay, and 1- to $2.5-\mathrm{Hz}$ generalized slow spike and wave activity on EEG. These patients respond poorly to antiepileptic medication, and their neurocognitive outcome is generally poor. Radionuclide imaging can play an important role in prognostication, as well as treatment planning, in some of these patients (54-58).

PET Imaging. ${ }^{18} \mathrm{~F}-\mathrm{FDG}$ PET has revealed 4 metabolic patterns in these patients: unilateral focal, unilateral diffuse, and bilateral diffuse hypometabolism, as well as normal 
glucose metabolism (54). Patients with a unilateral focal pattern may occasionally be considered for cortical resection if there is good concordance between PET and ictal EEG findings (58), although surgical outcome usually remains poor.

SPECT Imaging. Few SPECT imaging data are available for this condition. Interictal SPECT usually shows multiple areas of hypoperfusion (59).

\section{Sturge-Weber Syndrome (SWS)}

SWS is a rare sporadic neurocutaneous syndrome characterized by facial cutaneous angioma (unilateral or bilateral port-wine stains) typically located in the distributions of the trigeminal nerve, associated with ipsilateral leptomeningeal angiomatosis and congenital glaucoma. The clinical course of SWS is variable. It may be clinically static but can be a progressive neurologic condition leading to mental retardation, hemiplegia, visual deficit, and intractable epilepsy, with seizures developing in almost $75 \%-90 \%$ of SWS children.

PET Imaging. Structural neuroimaging, such as CT and MR imaging, is usually used to establish the diagnosis of SWS and define the extent of the angioma, which may involve the entire hemisphere or portions of the hemisphere (often posteriorly); however, structural imaging usually underestimates the actual extent. Functional imaging, such as ${ }^{18} \mathrm{~F}-\mathrm{FDG}$ PET, frequently demonstrates a much larger area of abnormal cortex, extending beyond the abnormality seen on CT or MR imaging $(60,61)$. On the other hand, in some cases ${ }^{18} \mathrm{~F}-\mathrm{FDG}$ PET may be better at predicting the functional status of brain that appears to be abnormal on MR imaging, thus providing information important not only for prognosis but also for planning any therapeutic intervention, such as surgery (Fig. 3). ${ }^{18} \mathrm{~F}-$ FDG PET is also better at assessing the progression of the disease and provides some useful prognostic information. Generally, hypometabolism is seen on ${ }^{18} \mathrm{~F}$-FDG PET in the involved cortex; however, affected children may show a paradoxic pattern of increased glucose metabolism interictally in the cortex underlying the leptomeningeal angioma early in the course (60). This pattern typically occurs in young children ( $<2$ y old), shortly before or after their first seizure and is not related to ongoing seizures or interictal spikes. Follow-up PET studies showed that cortical hypermetabolism, in these cases, is a transient phenomenon and invariably switches to hypometabolism in older children. It has been hypothesized that interictal hypermetabolism in young children with SWS may reflect a transient increase of metabolic demand in cortex undergoing excitotoxic tissue damage. Affected children often (but not always) develop intractable seizures requiring surgical resection (62), and it appears that the presence of early cortical hypermetabolism on PET may be an imaging marker of subsequent severe epilepsy, requiring early surgical intervention (62). In some young patients, serial ${ }^{18}$ F-FDG PET scans show rapidly progressing and severe hypometabolism in the affected area, probably because of rapid demise of the brain tissue associated with the angioma; these patients will have improvement in seizure status and paradoxic preservation of cognitive function and therefore may not require surgical intervention

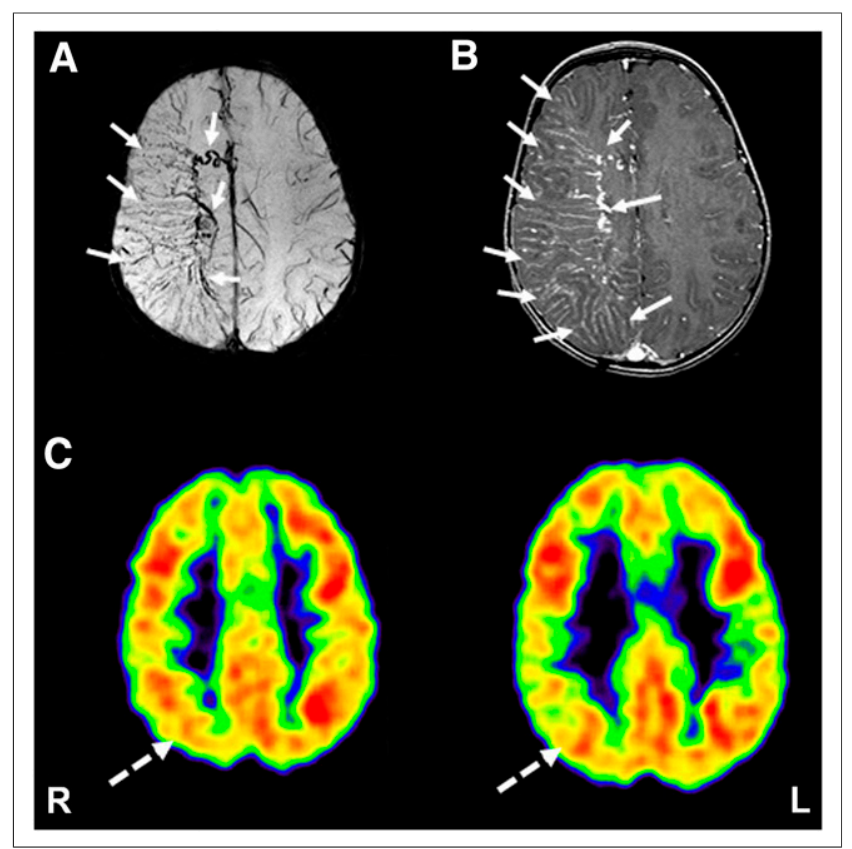

FIGURE 3. Susceptibility-weighted MR imaging (A), gadolinium-enhanced T1-weighted MR imaging $(\mathrm{B})$, and ${ }^{18} \mathrm{~F}-$ FDG PET imaging (C) in child with SWS. Although both susceptibility-weighted and contrast-enhanced MR imaging showed extensive deep venous abnormalities involving frontoparietal cortex (solid arrows), ${ }^{18} \mathrm{~F}-\mathrm{FDG}$ PET showed smaller area of hypometabolism, involving parietal cortex only (dashed arrow), suggesting preserved neuronal function despite extensive structural abnormalities.

(Fig. 4) (63). This observation suggests that functional reorganization occurs more readily when unilateral cortex is severely damaged at an early age. It is likely that rapid demise of the affected areas, especially at younger ages, can facilitate more effective reorganization. Indeed, ${ }^{18}$ F-FDG PET studies demonstrated increased metabolism, likely indicating functional reorganization, in the contralateral occipital cortex of children with SWS and severe ipsilateral occipital damage (64). On the other hand, persistent mild hypometabolism of the lesion may indicate ongoing functional disturbance and these patients may show persistent seizures and developmental arrest (65). These are the patients who require surgical intervention for seizure control and possible cognitive improvement by promoting effective reorganization in the contralateral hemisphere while brain plasticity is still at a maximum during development. In SWS, detrimental metabolic changes occur mostly before 3-4 y of age (61), coinciding with a sharp increase in developmentally regulated cerebral metabolic demand (66). Progressive hypometabolism is associated with high seizure frequency in these children. However, metabolic abnormalities may remain limited or even partially recover later in some children with well-controlled seizures. Metabolic recovery accompanied by neurologic improvement suggests a critical window for therapeutic intervention in children with unilateral SWS (61).

SPECT Imaging. Perfusion SPECT, using ${ }^{133} \mathrm{Xe}$, shows hyperperfusion in the lesion even before seizure onset 


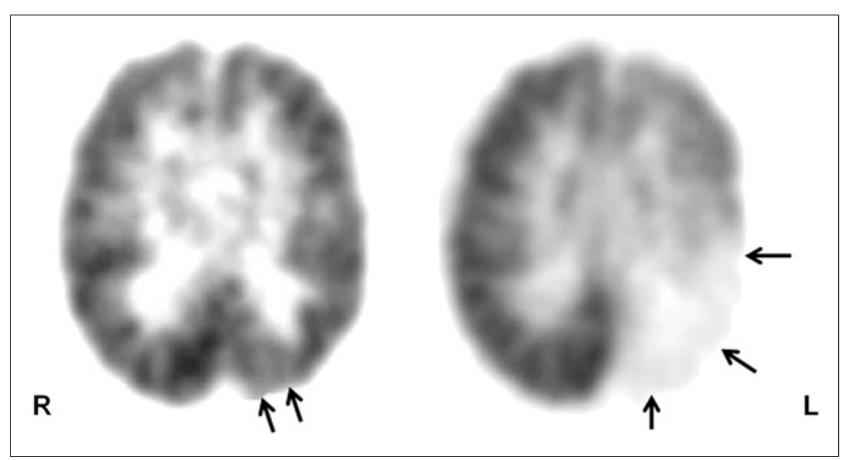

FIGURE 4. Serial ${ }^{18}$ F-FDG PET scans, performed at $18 \mathrm{mo}$ (left) and $6 \mathrm{y}$ (right) old, respectively, show progression of cortical hypometabolism (arrows) in both extent and severity, indicating degenerative changes in brain tissue associated with angioma in child with SWS and meningeal hemangioma of left posterior quadrant. This rapid progression represents demise of abnormal brain tissue and is akin to auto-resection; this child showed improvement in both seizure status and cognitive function.

(67), analogous to the transient hypermetabolism seen on ${ }^{18} \mathrm{~F}$-FDG PET $(60,61)$. After the age of $1 \mathrm{y}$, these areas typically show hypoperfusion, as revealed by another ${ }^{133} \mathrm{Xe}$ SPECT study (68). In a single case report on a patient with failed functional hemispherectomy, ictal ethylcysteinate dimer SPECT showed hyperperfusion in the residual lesion with falsely lateralized EEG; further surgery resulted in freedom from seizures (69).

\section{Hemimegalencephaly}

Hemimegalencephaly is a severe congenital malformation with a unilateral enlarged and defectively developed hemisphere and intractable seizures. PET and SPECT usually show a variable appearance in the involved hemisphere: hypo- or hypermetabolism on ${ }^{18}$ F-FDG PET and hypo- or hyperperfusion on hexamethylpropyleneamine oxime or ethylcysteinate dimer SPECT, depending on the seizure status at the time of scanning. Early hemisphere disconnection in these children may lead to seizure control and improved cognitive development, provided the other hemisphere is normal. Therefore, the main role of PET or SPECT is the evaluation of the apparently normal hemisphere (Fig. 5). In children with hemimegalencephaly, ${ }^{18}$ F-FDG PET often shows additional, less pronounced, abnormalities in the opposite hemisphere, which probably accounts for the suboptimal cognitive outcome even with complete seizure control after surgical removal of the profoundly abnormal hemisphere (70). Thus, ${ }^{18} \mathrm{~F}-\mathrm{FDG}$ PET can be useful in such cases to assess the functional integrity of the contralateral hemisphere before hemispherectomy and help predict cognitive outcome.

\section{Rasmussen Encephalitis and Epilepsy Related to Suspected Inflammatory Etiology}

Rasmussen encephalitis is a rare form of chronic focal encephalitis characterized by intractable focal seizures, hemiplegia, and progressive encephalopathy, associated with inflammation and progressive atrophy of a single hemisphere. Because of the progressive neurologic deterioration that

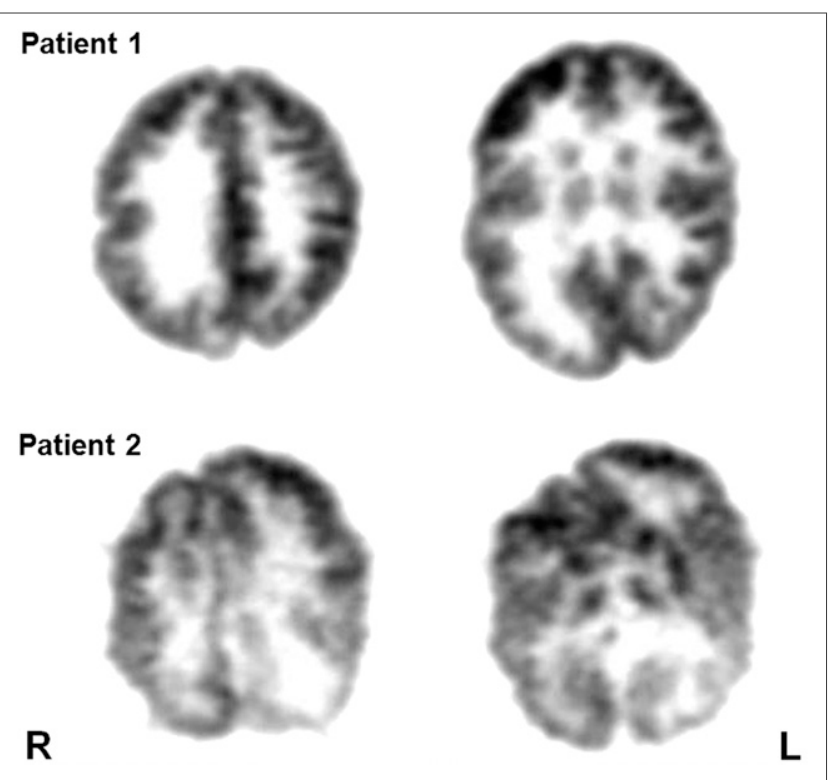

FIGURE 5. ${ }^{18} \mathrm{~F}-\mathrm{FDG}$ PET scans of 2 patients with intractable epilepsy due to hemimegalencephaly, right-sided in patient 1 and left-sided in patient 2. Although contralateral hemisphere looks relatively normal in first patient, contralateral hemisphere in second patient looks abnormal, indicating functional impairment of this hemisphere also. Hemispherectomy will have much better outcome in first patient, but seizure and neurocognitive outcome will be poor in second patient.

accompanies Rasmussen encephalitis, aggressive treatment is necessary, of which surgical hemispherectomy is the mainstay. Thus, early diagnosis is necessary. Progressive, lateralized cerebral hemiatrophy demonstrated by CT and MR imaging is the characteristic finding in Rasmussen encephalitis. However, during the early stages of the disease, structural imaging results may be normal. In this situation, functional neuroimaging using SPECT or PET scanning can detect functional abnormalities $(65,71,72)$.

PET Imaging. ${ }^{18} \mathrm{~F}-\mathrm{FDG}$ PET can show both hyper- and hypometabolism in cases of Rasmussen encephalitis, depending on the seizure status during the scan $(73,74)$. It can particularly help in the unequivocal identification of the affected cerebral hemisphere in patients whose MR imaging findings are subtle or distributed bilaterally (75). ${ }^{18} \mathrm{~F}$-FDG PET can further help in guiding the site of biopsy when indicated, thus assisting in earlier diagnosis. Interictal hypometabolism expands over time and usually precedes the anatomic changes, thus further helping to clarify the equivocal cases or assess the functional impairment and its evolution (73). ${ }^{18} \mathrm{~F}$-FDG PET can demonstrate the order of progression of cerebral glucose metabolism abnormalities during the early and late stages of Rasmussen encephalitis (65). During the early stages $(<1 \mathrm{y}$ from seizure onset), abnormal glucose metabolism is seen typically in the frontal and temporal regions and less frequently in parietal areas, whereas the posterior cortex is preserved. In the later stages of the disease ( $>1 \mathrm{y}$ after onset of seizures), more extensive hemispheric involvement is seen, including 
the occipital cortex, but the functional abnormalities remained lateralized. Therefore, identification of the most involved areas by ${ }^{18} \mathrm{~F}-\mathrm{FDG}$ PET, even during the early stages when MR imaging findings are usually normal, may serve to guide the site of brain biopsy and, therefore, facilitate the diagnosis and early treatment of the disease.

Neuroinflammation is the underlying cause for intractable epilepsy in Rasmussen encephalitis, as well as in some other epileptic conditions. Neuroinflammation is mediated by activated microglia, whose detection is not possible with current radiologic methods or biochemical techniques; however, they can be imaged with PET tracers binding to the activated microglia. ${ }^{11} \mathrm{C}-(R)-[1-(2-c h l o r o p h e n y l)-$ $N$-methyl- $N$-(1-methylpropyl)-3-isoquinolinecarboxamide ] $\left({ }^{11} \mathrm{C}-\mathrm{PK} 11195\right)$ is one such PET tracer that binds specifically to the translocator protein receptors, predominantly expressed by the activated microglia in cases of neuroinflammation, thus making the in vivo detection of neuroinflammation possible (76). PET scanning using ${ }^{11} \mathrm{C}-\mathrm{PK} 11195$ can help in the early diagnosis of Rasmussen syndrome or other inflammatory conditions with intractable seizures for which CT and MR imaging findings are often normal for several months after the clinical manifestation of the disease (Fig. 6). Localization of the most affected brain regions may also provide a guide in deciding the site of brain biopsy to avoid sampling errors and can help in the surgical removal of that region (77).

SPECT Imaging. Perfusion SPECT shows hyper- or hypoperfusion of the affected cortex, depending on the seizure status during the tracer injection, and can guide the histopathologic evaluation or surgical planning (78).

\section{Neonatal Seizures}

Seizures occur more frequently in the neonatal period than at any other time of life, and premature and low-birthweight babies have a much higher rate of neonatal seizures than do full-term and normal-birth-weight babies (79). Further, neonatal seizures are a risk factor for refractory epilepsy during childhood, necessitating earlier diagnosis and intervention. The most important factor in the therapy of neonatal seizures is accurate diagnosis. In neonates with no obvious metabolic abnormality, structural imaging studies (particularly MR imaging) may be useful to detect major

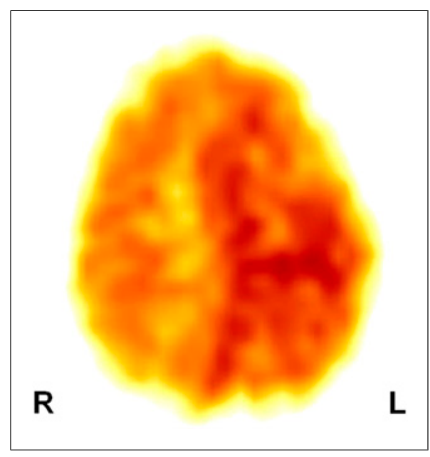

FIGURE 6. ${ }^{11} \mathrm{C}-(R)-\mathrm{PK} 11195$ PET scan showing increased binding in right hemisphere, indicating neuroinflammation mediated by activated microglia, in child with suspected Rasmussen encephalitis.

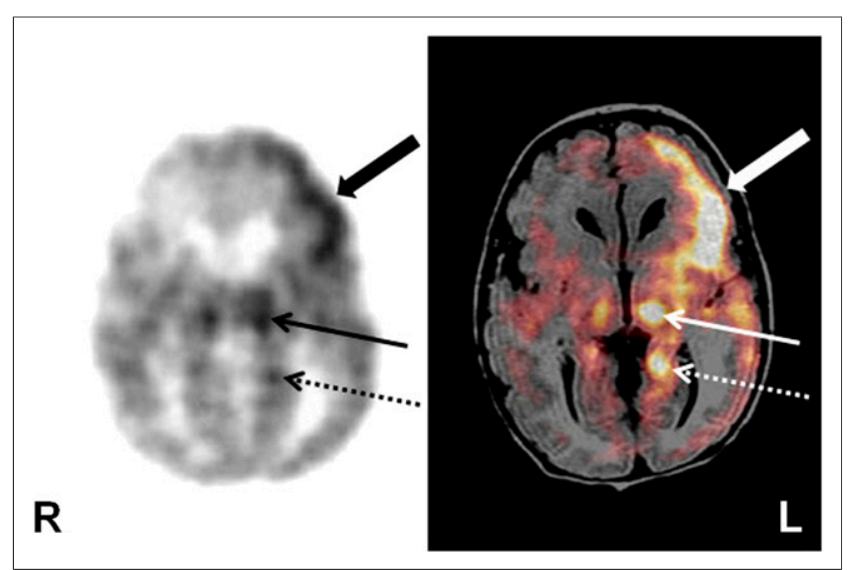

FIGURE 7. ${ }^{18} \mathrm{~F}-\mathrm{FDG}$ PET scan alone (left) and coregistered with MR scan (right) in newborn with neonatal seizure shows hypermetabolism in left frontal cortex (thick arrow), as child was seizing during ${ }^{18} \mathrm{~F}-\mathrm{FDG}$ uptake period. Left thalamus (thin solid arrow) and parahippocampal region (thin dashed arrow) are also hypermetabolic, likely because of their involvement in seizure propagation, without any obvious structural abnormalities seen on MR imaging.

malformations that are associated with seizures. However, in this age group the diagnostic value of MR imaging in identifying subtle cortical developmental malformationsone of the commonest underlying causes of partial seizures-is limited. In fact, in children less than $2 \mathrm{y}$ old, even macroscopic cortical malformations may not be apparent on MR imaging until myelination processes advance and the distinction between gray and white matter becomes clearer. The recognition of the underlying etiology of neonatal seizures is important because some etiologies indicate specific treatments that when implemented early in the course may improve neurologic outcome. Therefore, radionuclide imaging, such as PET, can play an important role in these cases by demonstrating metabolic abnormality when structural imaging may be equivocal because of the inherent limitation of these techniques in younger brains (Fig. 7).

\section{CONCLUSION}

PET and SPECT can play an important role in the evaluation of various epileptic syndromes, particularly those with unknown causes, by revealing some underlying abnormalities, thus not only helping in understanding their etiopathogenesis but also assisting in developing and administering various therapeutic interventions, including resective surgery for intractable epilepsy.

\section{REFERENCES}

1. Dulac O, Plouin P, Jambaque I. Predicting favorable outcome in idiopathic West syndrome. Epilepsia. 1993;34:747-756.

2. Dulac O, Plouin P, Jambaque I, Motte J. Benign epileptic infantile spasms [in French]. Rev Electroencephalogr Neurophysiol Clin. 1986;16: 371-382.

3. Chugani HT, Shewmon DA, Shields WD, et al. Surgery for intractable infantile spasms: neuroimaging perspectives. Epilepsia. 1993;34:764-771. 
4. Chugani HT, Shields WD, Shewmon DA, Olson DM, Phelps ME, Peacock WJ. Infantile spasms: I. PET identifies focal cortical dysgenesis in cryptogenic cases for surgical treatment. Ann Neurol. 1990;27:406-413.

5. Chugani HT, Conti JR. Etiologic classification of infantile spasms in 140 cases: role of positron emission tomography. J Child Neurol. 1996;11:44-48.

6. Asarnow RF, LoPresti C, Guthrie D, et al. Developmental outcomes in children receiving resection surgery for medically intractable infantile spasms. Dev Med Child Neurol. 1997;39:430-440.

7. Branch CE, Dyken PR. Choroid plexus papilloma and infantile spasms. Ann Neurol. 1979;5:302-304.

8. Jonas R, Asarnow RF, LoPresti C, et al. Surgery for symptomatic infantonset epileptic encephalopathy with and without infantile spasms. Neurology. 2005;64:746-750.

9. Kramer U, Sue WC, Mikati MA. Focal features in West syndrome indicating candidacy for surgery. Pediatr Neurol. 1997;16:213-217.

10. Mimaki T, Ono J, Yabuuchi H. Temporal lobe astrocytoma with infantile spasms. Ann Neurol. 1983;14:695-696.

11. Palm DG, Brandt M, Korinthenberg R. West syndrome and Lennox-Gastaut syndrome in children with porencephalic cysts: long-term follow-up after neurosurgical treatment. In: Niedermeyer E, Degen R, eds. The Lennox-Gastaut syndrome. New York, NY: Alan R. Liss; 1988:419-426.

12. Ruggieri V, Caraballo R, Fejerman N. Intracranial tumors and West syndrome. Pediatr Neurol. 1989;5:327-329.

13. Sugimoto T, Otsubo H, Hwang PA, Hoffman HJ, Jay V, Snead OC III. Outcome of epilepsy surgery in the first three years of life. Epilepsia. 1999;40:560-565.

14. Uthman BM, Reid SA, Wilder BJ, Andriola MR, Beydoun AA. Outcome for West syndrome following surgical treatment. Epilepsia. 1991;32:668-671.

15. Wyllie E, Comair YG, Kotagal P, Bulacio J, Bingaman W, Ruggieri P. Seizure outcome after epilepsy surgery in children and adolescents. Ann Neurol. 1998;44:740-748.

16. Yum MS, Ko TS, Lee JK, Hong S, Kim DS, Kim J. Surgical treatment for localization-related infantile spasms: excellent long-term outcomes. Clin Neurol Neurosurg. 2011;113:213-217.

17. Chugani HT, Asano E, Sood S. Infantile spasms: who are the ideal surgical candidates? Epilepsia. 2010;51(suppl 1):94-96.

18. Chugani HT, Da Silva E, Chugani DC. Infantile spasms: III. Prognostic implications of bitemporal hypometabolism on positron emission tomography. Ann Neurol. 1996;39:643-649.

19. Chiron C, Dulac O, Bulteau C, et al. Study of regional cerebral blood flow in West syndrome. Epilepsia. 1993;34:707-715.

20. Haginoya K, Kon K, Takayanagi M, et al. Heterogeneity of ictal SPECT findings in nine cases of West syndrome. Epilepsia. 1998;39(suppl 5):26-29.

21. Haginoya K, Munakata M, Yokoyama H, et al. Mechanism of tonic spasms in West syndrome viewed from ictal SPECT findings. Brain Dev. 2001;23:496501.

22. Hwang PA, Otsubo H, Koo BK, et al. Infantile spasms: cerebral blood flow abnormalities correlate with EEG, neuroimaging, and pathologic findings. $P e$ diatr Neurol. 1996;14:220-225.

23. Miyazaki M, Hashimoto T, Fujii E, Tayama M, Kuroda Y. Infantile spasms: localized cerebral lesions on SPECT. Epilepsia. 1994;35:988-992.

24. Sztriha L, al Suhaili AR, Prais V. Cortical hypoperfusion in symptomatic West syndrome: a SPECT study. Eur J Radiol. 1997;25:20-25.

25. Chugani HT, Shewmon DA, Sankar R, Chen BC, Phelps ME. Infantile spasms: II. Lenticular nuclei and brain stem activation on positron emission tomography. Ann Neurol. 1992;31:212-219.

26. Mori K, Toda Y, Hashimoto T, et al. Patients with West syndrome whose ictal SPECT showed focal cortical hyperperfusion. Brain Dev. 2007;29:202-209.

27. Kakisaka Y, Haginoya K, Ishitobi M, et al. Utility of subtraction ictal SPECT images in detecting focal leading activity and understanding the pathophysiology of spasms in patients with West syndrome. Epilepsy Res. 2009;83:177-183.

28. Haginoya K, Kon K, Yokoyama H, et al. The perfusion defect seen with SPECT in West syndrome is not correlated with seizure prognosis or developmental outcome. Brain Dev. 2000;22:16-23.

29. Evans LT, Morse R, Roberts DW. Epilepsy surgery in tuberous sclerosis: a review. Neurosurg Focus. 2012;32:E5.

30. Osborne JP, Fryer A, Webb D. Epidemiology of tuberous sclerosis. Ann N Y Acad Sci. 1991;615:125-127.

31. Perot P, Weir B, Rasmussen T. Tuberous sclerosis: surgical therapy for seizures. Arch Neurol. 1966;15:498-506.

32. Jansen FE, van Huffelen AC, Algra A, van Nieuwenhuizen O. Epilepsy surgery in tuberous sclerosis: a systematic review. Epilepsia. 2007;48:1477-1484.

33. Kagawa K, Chugani DC, Asano E, et al. Epilepsy surgery outcome in children with tuberous sclerosis complex evaluated with alpha- $\left[{ }^{11} \mathrm{C}\right]$ methyl-L-tryptophan positron emission tomography (PET). J Child Neurol. 2005;20:429-438.
34. Lachhwani DK, Pestana E, Gupta A, Kotagal P, Bingaman W, Wyllie E. Identification of candidates for epilepsy surgery in patients with tuberous sclerosis. Neurology. 2005;64:1651-1654.

35. Teutonico F, Mai R, Devinsky O, et al. Epilepsy surgery in tuberous sclerosis complex: early predictive elements and outcome. Childs Nerv Syst. 2008;24: 1437-1445.

36. Weiner HL, Carlson C, Ridgway EB, et al. Epilepsy surgery in young children with tuberous sclerosis: results of a novel approach. Pediatrics. 2006;117: 1494-1502.

37. Asano E, Chugani DC, Muzik O, et al. Multimodality imaging for improved detection of epileptogenic foci in tuberous sclerosis complex. Neurology. 2000;54:1976-1984.

38. Chandra PS, Salamon N, Huang J, et al. FDG-PET/MRI coregistration and diffusion-tensor imaging distinguish epileptogenic tubers and cortex in patients with tuberous sclerosis complex: a preliminary report. Epilepsia. 2006;47:15431549.

39. Karenfort M, Kruse B, Freitag H, Pannek H, Tuxhorn I. Epilepsy surgery outcome in children with focal epilepsy due to tuberous sclerosis complex. Neuropediatrics. 2002;33:255-261.

40. Ohta Y, Nariai T, Akimoto $\mathrm{H}$, et al. Tuberous sclerosis: epileptogenicity and multimodal presurgical evaluations. Childs Nerv Syst. 2001;17:313-319.

41. Wu JY, Salamon N, Kirsch HE, et al. Noninvasive testing, early surgery, and seizure freedom in tuberous sclerosis complex. Neurology. 2010;74:392398.

42. Rintahaka PJ, Chugani HT. Clinical role of positron emission tomography in children with tuberous sclerosis complex. J Child Neurol. 1997;12:4252 .

43. Szelies B, Herholz K, Heiss WD, et al. Hypometabolic cortical lesions in tuberous sclerosis with epilepsy: demonstration by positron emission tomography. J Comput Assist Tomogr. 1983;7:946-953.

44. Chugani HT, Luat AF, Kumar A, Govindan R, Pawlik K, Asano E. Alpha- $\left[{ }^{11} \mathrm{C}\right]-$ methyl-L-tryptophan-PET in 191 patients with tuberous sclerosis complex. Neurology. 2013;81:674-680.

45. Fedi M, Reutens DC, Andermann F, et al. Alpha- $\left[{ }^{11} \mathrm{C}\right]-$ methyl-L-tryptophan PET identifies the epileptogenic tuber and correlates with interictal spike frequency. Epilepsy Res. 2003;52:203-213.

46. Chugani DC, Muzik O, Chakraborty P, Mangner T, Chugani HT. Human brain serotonin synthesis capacity measured in vivo with alpha-[C-11]methyl-L-tryptophan. Synapse. 1998;28:33-43.

47. Juhász C, Chugani DC, Asano E, et al. Alpha $\left[{ }^{11} \mathrm{C}\right]$ methyl-L-tryptophan positron emission tomography scanning in 176 patients with intractable epilepsy [abstract]. Ann Neurol. 2002(suppl):S118.

48. Asano E, Chugani DC, Muzik O, et al. Autism in tuberous sclerosis complex is related to both cortical and subcortical dysfunction. Neurology. 2001;57:12691277.

49. Eluvathingal TJ, Behen ME, Chugani HT, et al. Cerebellar lesions in tuberous sclerosis complex: neurobehavioral and neuroimaging correlates. J Child Neurol. 2006;21:846-851.

50. Aboian MS, Wong-Kisiel LC, Rank M, Wetjen NM, Wirrell EC, Witte RJ. SISCOM in children with tuberous sclerosis complex-related epilepsy. Pediatr Neurol. 2011;45:83-88.

51. Koh S, Jayakar P, Resnick T, Alvarez L, Liit RE, Duchowny M. The localizing value of ictal SPECT in children with tuberous sclerosis complex and refractory partial epilepsy. Epileptic Disord. 1999;1:41-46.

52. Kuki I, Kawawaki H, Oba S, Okazaki S, Ikeda H, Tomiwa K. No To Hattatsu. 2008;40:54-56.

53. Mori K, Mori T, Toda Y, et al. Decreased benzodiazepine receptor and increased GABA level in cortical tubers in tuberous sclerosis complex. Brain Dev. 2012;34:478-486.

54. Chugani HT, Mazziotta JC, Engel J Jr, Phelps ME. The Lennox-Gastaut syndrome: metabolic subtypes determined by 2 -deoxy-2 $\left[{ }^{18} \mathrm{~F}\right]$ fluoro-D-glucose positron emission tomography. Ann Neurol. 1987;21:4-13.

55. Gur RC, Sussman NM, Alavi A, et al. Positron emission tomography in two cases of childhood epileptic encephalopathy (Lennox-Gastaut syndrome). Neurology. 1982;32:1191-1194.

56. Hur YJ, Kang HC, Kim DS, Choi SR, Kim HD, Lee JS. Uncovered primary seizure foci in Lennox-Gastaut syndrome after corpus callosotomy. Brain Dev. 2011;33:672-677.

57. Theodore WH, Rose D, Patronas N, et al. Cerebral glucose metabolism in the Lennox-Gastaut syndrome. Ann Neurol. 1987;21:14-21.

58. You SJ, Lee JK, Ko TS. Epilepsy surgery in a patient with Lennox-Gastaut syndrome and cortical dysplasia. Brain Dev. 2007;29:167-170.

59. Heiskala H, Launes J, Pihko H, Nikkinen P, Santavuori P. Brain perfusion SPECT in children with frequent fits. Brain Dev. 1993;15:214-218. 
60. Chugani HT, Mazziotta JC, Phelps ME. Sturge-Weber syndrome: a study of cerebral glucose utilization with positron emission tomography. J Pediatr. 1989; 114:244-253.

61. Juhasz C, Batista CE, Chugani DC, Muzik O, Chugani HT. Evolution of cortical metabolic abnormalities and their clinical correlates in Sturge-Weber syndrome. Eur J Paediatr Neurol. 2007;11:277-284.

62. Alkonyi B, Chugani HT, Juhasz C. Transient focal cortical increase of interictal glucose metabolism in Sturge-Weber syndrome: implications for epileptogenesis. Epilepsia. 2011;52:1265-1272.

63. Behen ME, Juhasz C, Wolfe-Christensen C, et al. Brain damage and IQ in unilateral Sturge-Weber syndrome: support for a "fresh start" hypothesis. Epilepsy Behav. 2011;22:352-357.

64. Batista CE, Juhasz C, Muzik O, Chugani DC, Chugani HT. Increased visual cortex glucose metabolism contralateral to angioma in children with SturgeWeber syndrome. Dev Med Child Neurol. 2007;49:567-573.

65. Lee JS, Asano E, Muzik O, et al. Sturge-Weber syndrome: correlation between clinical course and FDG PET findings. Neurology. 2001;57:189-195.

66. Chugani HT, Phelps ME, Mazziotta JC. Positron emission tomography study of human brain functional development. Ann Neurol. 1987;22:487-497.

67. Pinton F, Chiron C, Enjolras O, Motte J, Syrota A, Dulac O. Early single photon emission computed tomography in Sturge-Weber syndrome. J Neurol Neurosurg Psychiatry. 1997;63:616-621.

68. Chiron C, Raynaud C, Tzourio N, et al. Regional cerebral blood flow by SPECT imaging in Sturge-Weber disease: an aid for diagnosis. J Neurol Neurosurg Psychiatry. 1989;52:1402-1409.

69. Bilgin O, Vollmar C, Peraud A, la Fougere C, Beleza P, Noachtar S. Ictal SPECT in Sturge-Weber syndrome. Epilepsy Res. 2008;78:240-243.
70. Rintahaka PJ, Chugani HT, Messa C, Phelps ME. Hemimegalencephaly: evaluation with positron emission tomography. Pediatr Neurol. 1993;9:21-28.

71. Burke GJ, Fifer SA, Yoder J. Early detection of Rasmussen's syndrome by brain SPECT imaging. Clin Nucl Med. 1992;17:730-731.

72. Kaiboriboon K, Cortese C, Hogan RE. Magnetic resonance and positron emission tomography changes during the clinical progression of Rasmussen encephalitis. J Neuroimaging. 2000;10:122-125.

73. Lee JS, Juhasz C, Kaddurah AK, Chugani HT. Patterns of cerebral glucose metabolism in early and late stages of Rasmussen's syndrome. J Child Neurol. 2001;16:798-805.

74. Tien RD, Ashdown BC, Lewis DV Jr, Atkins MR, Burger PC. Rasmussen's encephalitis: neuroimaging findings in four patients. AJR. 1992;158:1329-1332.

75. Fiorella DJ, Provenzale JM, Coleman RE, Crain BJ, Al-Sugair AA. ${ }^{18}$ Ffluorodeoxyglucose positron emission tomography and MR imaging findings in Rasmussen encephalitis. Am J Neuroradiol. 2001;22:1291-1299.

76. Banati RB, Goerres GW, Myers R, et al. $\left[{ }^{11} \mathrm{C}\right](\mathrm{R})-\mathrm{PK} 11195$ positron emission tomography imaging of activated microglia in vivo in Rasmussen's encephalitis. Neurology. 1999;53:2199-2203.

77. Kumar A, Chugani HT, Luat A, Asano E, Sood S. Epilepsy surgery in a case of encephalitis: use of ${ }^{11} \mathrm{C}-\mathrm{PK} 11195$ positron emission tomography. Pediatr Neurol. 2008;38:439-442.

78. Burneo JG, Hamilton M, Vezina W, Parrent A. Utility of ictal SPECT in the presurgical evaluation of Rasmussen's encephalitis. Can J Neurol Sci. 2006;33: $107-110$.

79. Lanska MJ, Lanska DJ, Baumann RJ, Kryscio RJ. A population-based study of neonatal seizures in Fayette County, Kentucky. Neurology. 1995;45:724-732. 